\title{
Estimation of Polar Cap Potential and the Role of PC Index
}

\author{
Ga-Hee Moon ${ }^{\dagger}$ \\ Daegu Science High School, Daegu 706-852, Korea
}

Polar cap potential has long been considered as an indicator for the amount of energy flowing in the magnetosphereionosphere system. Thus, the estimation of polar cap potential is important to understand the physical process of the magnetosphere. To estimate the polar cap potential in the Northern Hemisphere, merging electric field by Kan \& Lee (1979) is adopted. Relationships between the PC index and calculated merging electric field $\left(E^{*}\right)$ are examined during full-time and storm-time periods separately. For this purpose Dst, AL, and PC indices and solar wind data are utilized during the period from 1996-2003. From this linear relationship, polar cap potential $\left(\Phi^{*}\right)$ is estimated using the formula by Doyle \& Burke (1983). The values are represented as $58.1 \pm 26.9 \mathrm{kV}$ for the full-time period and $123.7 \pm 84.1 \mathrm{kV}$ for a storm-time period separately. Considering that the average value of polar cap potential of Doyle \& Burke (1983) is about $47 \mathrm{kV}$ during moderately quiet intervals with the S3-2 measurements, these results are similar to such. The monthly averaged variation of Dst, AL, and PC indices are then compared. The Dst and AL indices show distinct characteristics with peaks during equinoctial season whereas the average PC index according to the month shows higher values in autumn than in spring. The monthly variations of the linear correlation coefficients between solar wind parameters and geomagnetic indices are also examined. The PC-AL linear correlation coefficient is highest, being 0.82 with peaks during the equinoctial season. As with the AL index, the PC index may also prove useful for predicting the intensity of an auroral substorm. Generally, the linear correlation coefficients are shown low in summer due to conductance differences and other factors. To assess the role of the PC index during the recovery phase of a storm, the relation between the cumulative PC index and the duration is examined. Although the correlation coefficient lowers with the storm size, it is clear that the average correlation coefficient is high. There is a tendency that duration of the recovery phase is longer as the PC index increases.

Keywords: PC index, polar cap potential, merging electric field, Dst index, AL index

\section{INTRODUCTION}

The PC index (PCN, PCS) was designed to monitor polar cap magnetic activity generated by geoeffective solar wind parameters. The PC index measures the part of the DP2 currents calculated from the projection of the horizontal magnetic perturbation on the dawn-dusk direction. This index is derived from the magnetic perturbations measured at a single magnetometer station near the magnetic pole, Thule (PCN) or Vostok (PCS) in the Northern and Southern Hemispheres. First attempt to examine the polar cap magnetic activity was made by Troshichev et al. (1979). They proposed a polar cap magnetic activity index based on data from a single near pole station: Vostok (83.4 ${ }^{\circ}$ in the
Southern Hemisphere) and Thule (86.5 ${ }^{\circ}$ in the Northern Hemisphere). Troshichev \& Andrezen (1985) showed the ground geomagnetic disturbances measured at the Vostok station highly correlate with the merging electric field. Afterwards, the main principles of the PC index derivation as an indicator of magnetic activity in polar cap regions were formulated by Troshichev et al. (1988). They derived an ionospheric electric field from a merging electric field by mapping down along magnetic field lines with the use of the magnetic field lines convergence factor.

In solar wind-magnetosphere coupling, energy transfer from solar wind into the magnetosphere is one of the fundamental problems in magnetospheric physics. It is well known that the coupling function is important to understand (c) This is an open Access article distributed under the terms of the Creative Commons Attribution Non-Commercial License (http:// creativecommons.org/licenses/by-nc/3.0/) which premits unrestricted non-commercial use, distribution, and reproduction in any medium, provided the original work is properly cited.
Received Aug 10, 2012 Revised Aug 23, 2012 Accepted Aug 24, 2012 †Corresponding Author

E-mail: kafemoon@hanmail.net

Tel: +82-53-765-0012 Fax: +82-53-765-0023 
the relationships between ionosphere-magnetosphere and solar wind energy input. Perreault \& Akasofu (1978) showed that interplanetary energy flux is estimated on the basis of Poynting flux and its variations with the rate of energy dissipation in terms of three subjects for 15 major geomagnetic storms. They found that the energy flux entering the magnetosphere is dissipated through substorm processes. As a result, they concluded that a geomagnetic storm represents the combined influence of Poynting flux and the substorm process. Continuously suggesting a schematic illustration of reconnection geometry, Kan \& Lee (1979) introduced the equations of a merging electric field $\left(E_{\mathrm{m}}\right)$ and the polar cap potential $\left(\Phi_{\mathrm{m}}\right)$ at the magnetopause. The equations are as follows separately:

$$
\begin{aligned}
& E_{m}=v B_{T} \sin ^{2}\left(\frac{\theta}{2}\right) \\
& \Phi_{m}=v B_{T} \sin ^{2}\left(\frac{\theta}{2}\right) l_{0}
\end{aligned}
$$

In Eq. (1), $v$ is the magnitude of solar plasma flow velocity, $B_{T}$ is the transverse magnitude of the IMF, $\left(\sqrt{B_{y}^{2}+B_{z}^{2}}\right)$ and $\theta$ represents the angle between the Earth's magnetic field and the IMF total vector $\left(\cos ^{-1}\left(B_{z} / B\right)\right) \cdot l_{0}$ in Eq. (2) is the effective length of the $\mathrm{X}$ line in a schematic illustration by Kan \& Lee (1979).

On the other hand, Troshichev et al. (1996) examined the statistical dependence of the polar cap diameter on PC index of magnetic activity and the cross-polar cap voltage on PC index. In addition, they showed the relationship between observed cross polar cap voltage and various interplanetary quantities. Eq. (3) below is the obvious linear relationship

$$
\Phi_{p c}[k V]=19.35 P C+8.78
$$

with the correlation coefficient equaling 0.797 .

Since then, some researchers have investigated the relationship between merging electric field and the PC index through various methods (Troshichev et al. 2000). Using the Assimilative Mapping of Ionospheric Electrodynamics (AMIE) technique, Ridley \& Kihn (2004) determined cross polar cap potential, polar cap electric field, and polar cap area. It is noticeable that the seasonally dependent $y$-intercept is considered in their linear relationship between AMIE data and the PC index. Doyle \& Burke (1983) analyzed the S3-2 measurements of the polar cap potential during the period from August through to December, 1976 and obtained the linear relation between polar cap potential $\left(\Phi_{p c}\right)$ and interplanetary magnetic field $\left(B_{z}\right)$. They choose moderate quiet intervals data for analysis. And then, they used the least squares fit through the merging electric field of Kan-Lee model as follows:

$$
\Phi_{p c}=33.4+24.0 E_{m}(k V)
$$

Their measured potentials ranged from $170 \mathrm{kV}$ during a substorm to $12 \mathrm{kV}$ during two periods of a northward interplanetary magnetic field. Chun et al. (2002) also showed the linear relationship between the PC and crosspolar potential. They developed average patterns of Joule heating as a function of PC using 56 days of AMIE data derived from various case studies.

The polar cap potential tends to be saturated when the value of the merging electric field $\left(E_{m}\right)$ is high. Nagatsuma (2004) found that the degree of saturation does not depend on the intensity of the interplanetary magnetic field but actually depends on the value of $E_{m}$. In space physics, saturation means that physical quantities in the ionosphere are less than expected for a given strength of the solar wind driver. According to Borovsky \& Denton (2006), saturation of the polar cap tends to occur statistically during storm-times, solar maximum, and low-Mach number solar wind.

As a proxy substorm indicator, it has been argued that the PC index is useful. Indeed, some research has shown these relationships in various manners. Vennerstrøm et al. (1991) confirmed that there is indeed a high correlation between the PC and AE indices during winter and the equinox, the linear correlation coefficient being 0.8-0.9 for Thule. They convinced that the PC can be used as a fast available indicator of DP2 and DP1 activity in polar regions. As a function of time delay $\tau$, Troshichev \& Lukianova (2002) analyzed a distribution of coefficients of correlation (R) between PC and AE values during times of 12 magnetic storms in 2000. They found that each sharp increase of the PC index indicates a development of magnetospheric substorms in a matter of minutes. Pointing out that there is a certain relationship between the energy input into the magnetosphere and energy stored in the magnetospheric tail, it is suggested that the magnetosphere responds to the same variation of the solar wind parameters in a different manner. Takalo \& Timonen (1998) also studied that the PC and AU indices show similar dynamics through analyzing the structure function. It is generally believed that isolated substorms are often correlated with sudden changes in solar wind.

To study the relations of polar cap magnetic activity to magnetic disturbances in the auroral zone, Troshichev \& Janzhura (2009) analyzed the behavior of 62 repetitive bay-like magnetic disturbances. They further noted that the growth phase duration and intensity of magnetic 
disturbances in the auroral zone highly correlate with the PC growth rate. They also concluded that the PC index may be considered as a convenient proxy of the solar wind energy input of the magnetosphere. Lyatskaya et al. (2008) also investigated the relationship between substorm activity and magnetic disturbances in two polar caps. For this analysis, they used data from four years, 1990-1991 and 1997-1998, respectively. It is well known that the AL index represents westward auroral electrojets. They also examined the seasonal variation of the linear correlation coefficients $\mathrm{R}$, for the correlation of the AL index with the polar cap index.

In this study, I performed research in three parts. First, the relationship between the PC index and the calculated merging electric field $\left(E^{*}\right)$ using more data obtained from the period of 1996-2003 and estimated the polar cap potential $\left(\Phi^{*}\right)$ in the Northern Hemisphere. Especially, in order to compare full-time values and storm-time values, I analyzed that the relationship after dividing such into fulltime periods and storm-time periods. This point differs from previous works. While investigating the relationships, saturation was also found. Second, I also analyzed the relationship between the $\mathrm{PC}$ and $\mathrm{AL}$ indices for eight years from 1996-2003 to diagnose the PC index as a substorm indicator. In addition, the seasonal variations of correlation coefficients between solar wind parameters and the Dst, $\mathrm{AL}, \mathrm{PC}$ indices during these periods are also investigated. Third, substorm activity and variations of the PC index occur even during the recovery phase of storms. Admitting that the decay of the ring current is a dominant process of the recovery phase, it would be interesting to examine the actual contribution of the PC index. No previous works have been accomplished in regards to this subject until now. For this purpose, the correlation between the cumulative PC index and the duration of the recovery phase is examined.

\section{DATA AND METHODS}

The PC index used in this study was obtained from the Thule (Qaanaaq, 86.5 ${ }^{\circ}$ magnetic latitude in the Northern Hemisphere) ground magnetometer that is operated by the Danish Meteorological Institute (http://www.dmi. $\mathrm{dk}$ ). The solar wind data was provided via instruments on the advanced composition explorer (ACE) spacecraft. The geocentric solar magnetospheric coordinate system is adopted for solar wind velocity and interplanetary magnetic field data. The Dst and AL indices data for this study were provided by the World Data Center for Geomagnetism, Kyoto (http://wdc.kugi.kyoto-u.ac.jp). I used a one-hour average for the Dst index and a 5 minute average data for $E_{y^{\prime}}$
PC, AL during the period from 1996-2003. A magnetic storm is an accumulated phenomena expressed in terms of Dst, thus I used one hour data. On the other hand, 5 minute data were used for the purpose of identifying variations of such, as $E_{y^{\prime}} \mathrm{PC}, \mathrm{AL}$ stand for episodic phenomena. To examine the contribution of the PC index to the duration of the recovery phase of a magnetic storm with the storm size, storms are divided into three categories in terms of the minimum value of the Dst index, Dst ${ }_{\text {min }}$ : severe (Dst ${ }_{\text {min }}<-200 \mathrm{nT}$ ), intense $\left(-200 \mathrm{nT} \leq \mathrm{Dst}_{\min }<-100 \mathrm{nT}\right)$, and moderate $\left(-100 \mathrm{nT} \leq \mathrm{Dst}_{\min }\right.$ $<-50 \mathrm{nT}$ ). I did not include storm data in cases of no-data days or for judging non-monotonous storm data. As a result, a total of 152 magnetic storms for the main phase and 138 magnetic storms for the recovery phase during the 19962003 period are used.

\section{ANALYSIS AND RESULTS}

\subsection{Estimation of Polar Cap Potential from PC Index and Calculated Merging Electric Field $\left(E^{*}\right)$}

For the purpose of estimating the polar cap potential, the relationship between the PC index and the calculated merging electric field $\left(E^{*}\right)$ is examined using the PC index data at Thule and the solar wind data of the ACE satellite during the 1996-2003 period. First, to calculate the merging electric field, Eq. (1) by Kan \& Lee (1979) was used. Using Eq. (1), $E^{*}$ is obtained and the correlation between the

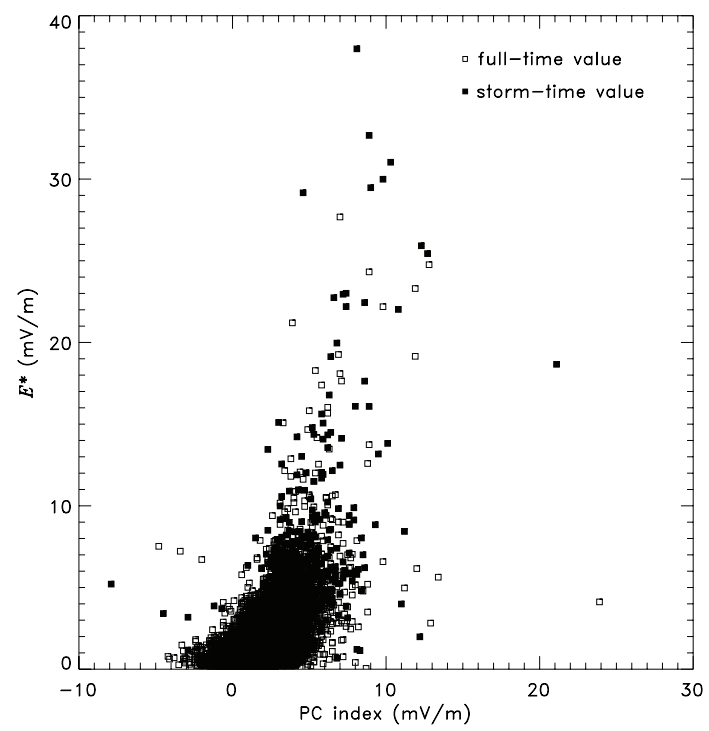

Fig. 1. The scatter plotting of PC index and the calculated merging electric field $\left(E^{*}\right)$ during the period of 1996-2003. Open and filled squares stand for one-hour averaged values during full-time period and stormtime period, respectively. 
Table 1. The linear relationships between $P C$ index and $E_{y} E^{*}$ during the period of 1996-2003.

\begin{tabular}{llc}
\hline & \multicolumn{1}{c}{ Full-time period } & \multicolumn{1}{c}{ Storm-time period } \\
\hline PC- $E_{y}$ & $E_{\mathrm{y}}=0.94(P C)-0.99(c c: 0.59)$ & $E_{y}=1.51(P C)-2.02(c c: 0.64)$ \\
PC- $E^{*}$ & $E^{*}=0.71(P C)+0.24(c c: 0.66)$ & $E^{*}=1.22(P C)-0.06(c c: 0.61)$ \\
\hline PC: polar cap.
\end{tabular}

PC index and $E^{*}$ was examined. Fig. 1 shows the scatter plots between the PC index and $E^{*}$ during the period from 1996-2003. In Fig. 1, the open and filled squares stand for one-hour averaged values during the full-time period and storm-time period, respectively. During these periods, 69,331 individual points of full-time including 1,623 stormtime points are shown. As shown in Fig. 1, although the PC data points are somewhat widely distributed, the PC index does not increase in accordance with $E^{*}$. This may be related to the saturation phenomenon. Table 1 shows the linear correlation equations and correlation coefficients between the PC-interplanetary electric field $\left(E_{y}\right)$ and the PC-calculated merging electric field $\left(E^{*}\right)$. The abbreviation cc stands for correlation coefficient. Compared with the relationships of PC- $E_{y}$, PC- $E^{*}$ shows a lower coefficient during the storm-time period as it may also be related to the saturation. As shown in Table 1, the slopes of the correlation equations differ. The slope during storm-time is higher than that of full-time by $71 \%$, indicating that a higher level of $E^{*}$ is shown during storm-time than at full-time in the same level of the PC index. Compared to Troshichev et al. (1996)'s study, the polar cap potential is higher in this study because the data set and periods differ. On the other hand, the average value of $E^{*}$ is calculated as 2.77 times higher during storm-time periods than full-time periods. The PC index is also shown as 3.58 times higher.

As noted in the previous section, Troshichev et al. (1996) investigated the relationship between polar cap potential and the PC index using only two months' worth of data. However, in this study, one-hour averaged data over 8 years were used for analysis and utilized the Doyle \& Burke (1983)'s empirical relationship after calculating $E^{*}$. Especially, the polar cap potential is estimated after dividing such into full-time and storm-time periods from 19962003. The results are as shown in Table 2. The estimated polar cap potential is calculated from $36.0 \mathrm{kV}$ to $1,266.3 \mathrm{kV}$ during storm-time periods. The average polar cap potential is estimated as $58.1 \pm 26.9 \mathrm{kV}$ during full-time and 123.7 $\pm 84.1 \mathrm{kV}$ during storm-time, respectively. The maximum value of the polar cap potential is recorded as being 1266.3 $\mathrm{kV}$ on 15 July 2000. Fig. 2 shows the variations of (a) IMF $B_{z^{\prime}}$ (b) PC index, (c) estimated polar cap potential, and (d) Dst index on 15 July 2000. As shown in Fig. 2a, after fluctuating for several hours, the IMF $B_{z}$ plunged to $-58.5 \mathrm{nT}$. At that
Table 2. Estimated polar cap potential $\left(\Phi^{*}\right)$ using the Doyle \& Burke (1983)'s empirical relations.

\begin{tabular}{|c|c|c|c|c|}
\hline \multicolumn{3}{|c|}{ Full-time period } & \multicolumn{2}{|c|}{ Storm-time period } \\
\hline & Average & Standard deviation & Average & Standard deviation \\
\hline$\Phi^{*}$ & 58.1 & 26.9 & 123.7 & 84.1 \\
\hline
\end{tabular}
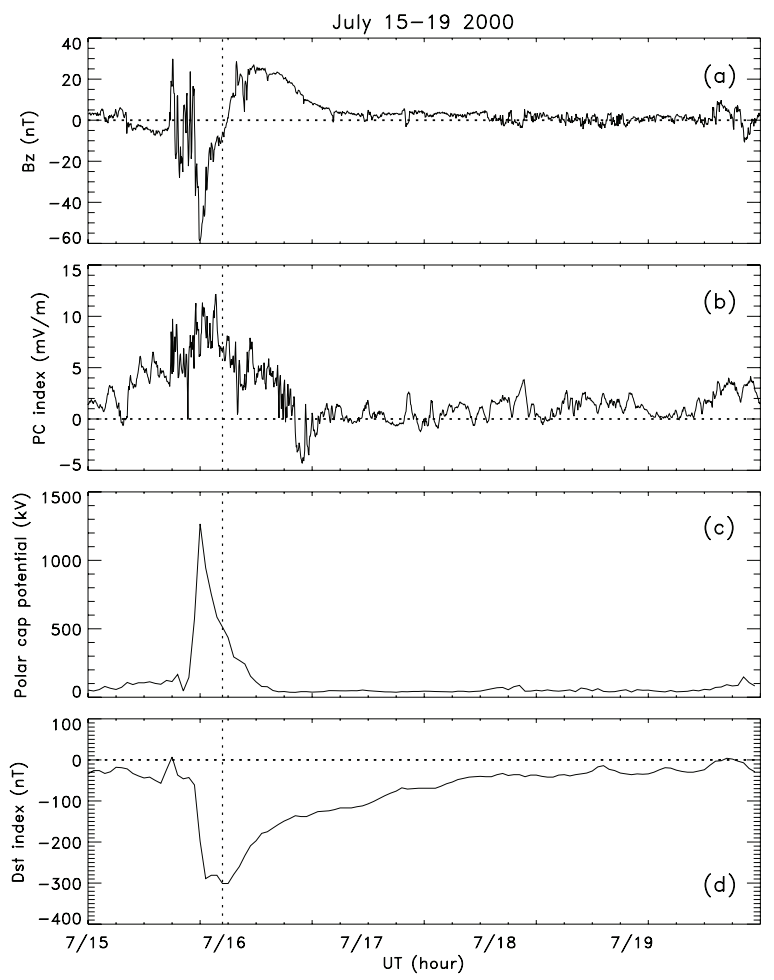

Fig. 2. Variations of (a) IMF $B z$, (b) PC index, (c) estimated polar cap potential, and (d) Dst index on 15-19 July 2000.

time, the PC index was also recorded above $10 \mathrm{mV} / \mathrm{m}$ several times as shown in Fig. 2b. It is well known that the polar cap potential is generally about $50 \mathrm{kV}$ under ordinary conditions, however, such changes up to a few hundred $\mathrm{kV}$ or exceeds $1,000 \mathrm{kV}$ during a magnetic storm period. Considering that the average value of the polar cap potential by Doyle \& Burke (1983) is about $47 \mathrm{kV}$ during moderate quiet intervals, these results are similar to such.

\subsection{Relationship Between the AL Index and PC Index}

Fig. 3 shows variations of (a) interplanetary electric field $\left(E_{y}\right)$, (b) PC index, (c) AL index, and (d) Dst index for 2225 September 1999. The horizontal axis denotes universal time and two vertical dotted lines represent the main phase of the storm. $E_{y}$ changes from a negative value to a positive value, and reached the maximum value being $12.84 \mathrm{mV} / \mathrm{m}$ at 21:55 UT on September 22 as shown in Fig. 3a. In Figs. 

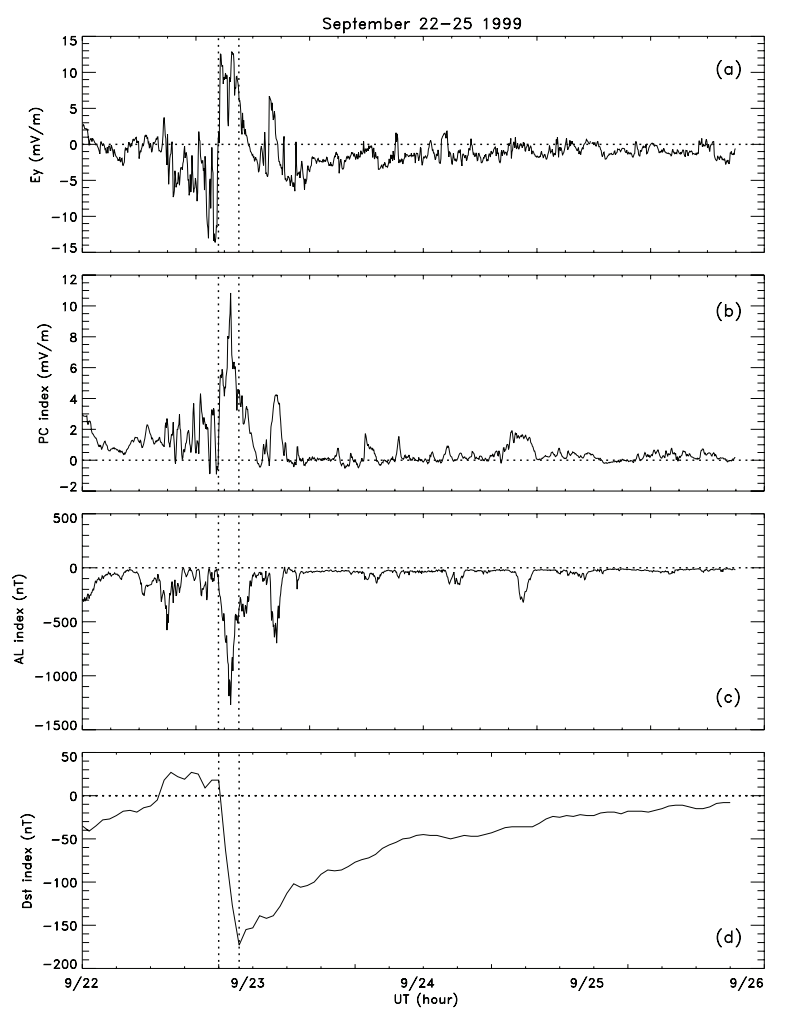

Fig. 3. Variations of (a) interplanetary electric field (Ey), (b) PC index, (c) AL index, and (d) Dst index for 22-25 September 1999. The horizontal axis denotes universal time and two vertical dotted line represent main phase of the storm.
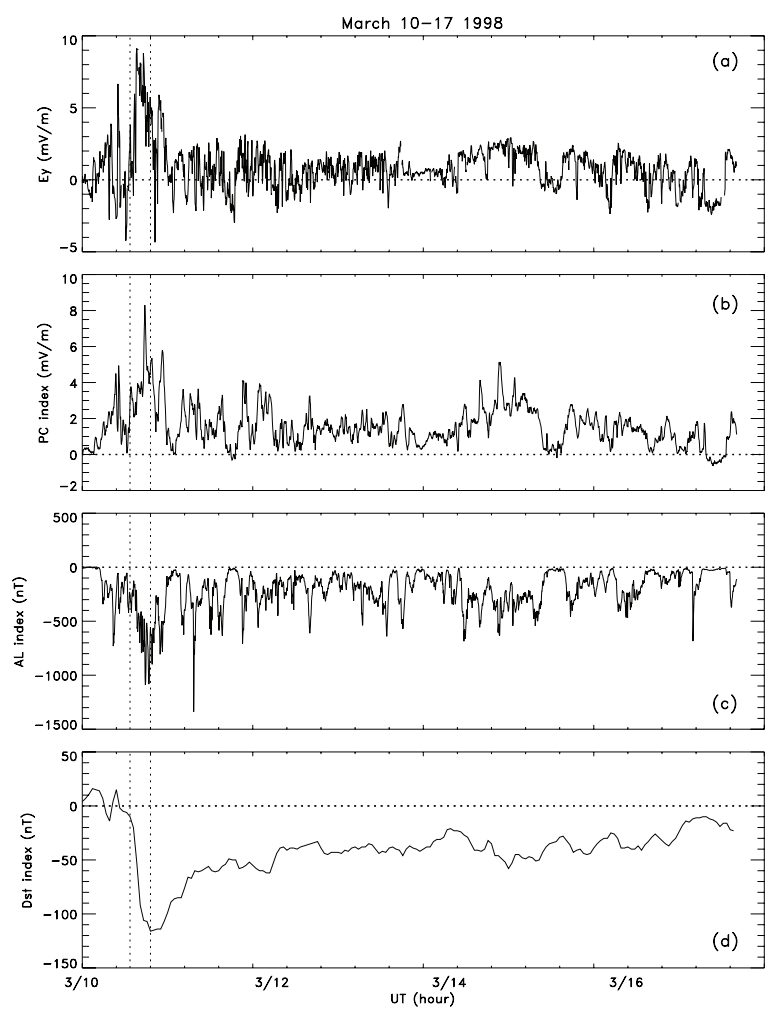

Fig. 4. Tha same as Fig. 3 but for 10-17 March 1998.
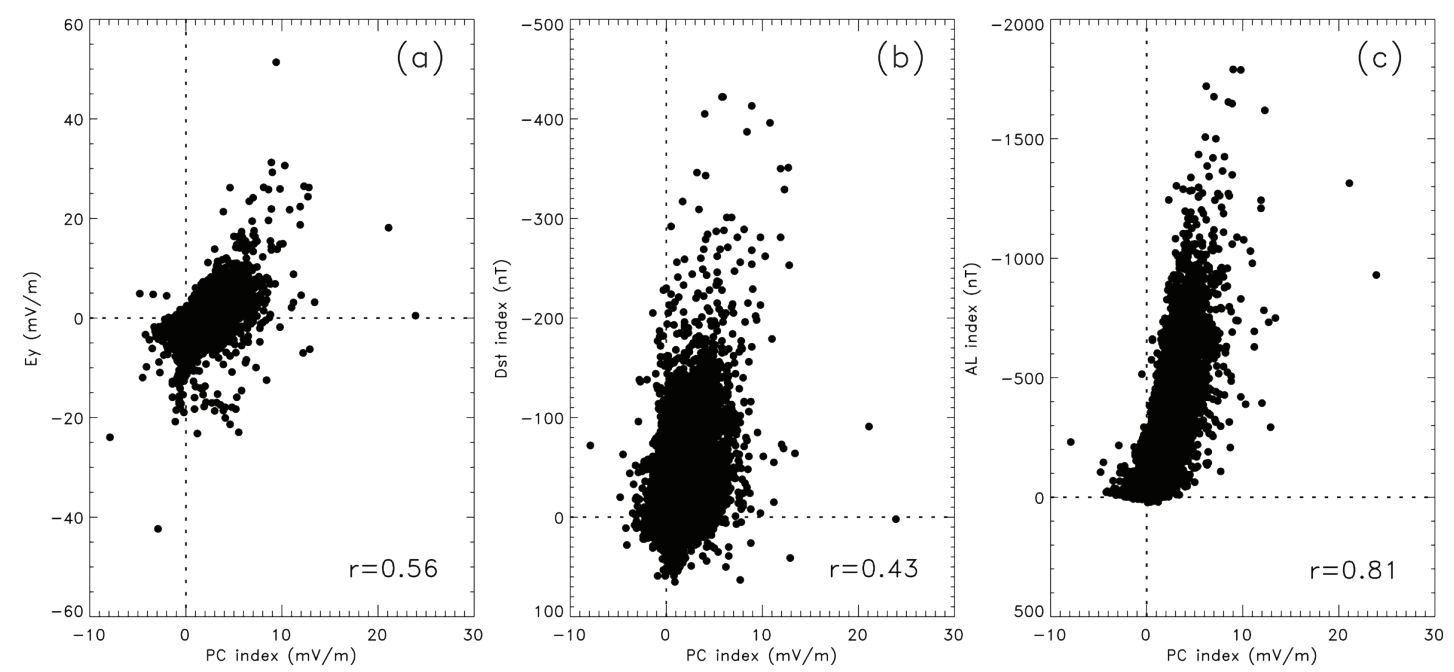

Fig. 5. Scatter plots between (a) $P C$ index and $E_{y^{\prime}}$ (b) PC index and Dst index, and (c) PC index and AL index during 1996-2003 period.

$3 \mathrm{~b}$ and $\mathrm{c}$, the PC index was recorded being the maximum value of $10.84 \mathrm{mV} / \mathrm{m}$ at 21:45 UT and the AL index had also reached the minimum value recorded as $-1,269 \mathrm{nT}$ at that time prior to Dst reaching the minimum value. As shown in Fig. 3d, the Dst index decreased rapidly for just
3 hours, and the minimum value of $-173 \mathrm{nT}$ at 00:00 UT was recorded on 23 September 1999. In Figs. 3b and c, the variation of $\mathrm{AL}$ and $\mathrm{PC}$ indices are very similar during main and recovery phases, both. Fig. 4 shows another example for the variations of $E_{y^{\prime}}$ PC index, AL index, and Dst index. 
As can be seen in Fig. 4, the variation of the PC index is also similar to that of the AL index rather than the $E_{y}$ variation. The Dst index decreased abruptly, followed by a moderate SSC, and was then recorded as the minimum value of -116 nT at 21:00 UT on March 10th. After the PC index increased up to $8.30 \mathrm{mV} / \mathrm{m}$ at 18:20 UT, the AL index also reached the minimum value as recorded as $-1,090 \mathrm{nT}$ at 18:30 UT during the main phase of magnetic storms. One can see many substorms for the recovery phase of magnetic storm shown in Fig. 4c. Whenever substorms occur during the recovery phase, the Dst index decreases repeatedly. As shown in Figs. 3 and 4, the variation of AL and PC indices indicate the close relationship between such. Fig. 5 shows the scatter plots between (a) PC- $E_{y^{\prime}}$ (b) PC-Dst, and (c) PCAL during the period from 1996-2003. According to Fig. 5, the correlation coefficient of the PC-AL is higher being 0.81 than those of PC- $E_{y}$, PC-Dst. The AL index is derived from geomagnetic variations from selected observations along the northern auroral zone and means westward auroral electrojects in the DP2 current system. On the other hand, the PC index is associated to field-aligned currents flowing to the poleward rim and Hall current in the polar cap. The high correlation of PC-AL denotes that the underlying current systems in the ionosphere are indeed connected to each other. Fig. 6 shows the monthly averaged variations of (a) Dst index, (b) AL index, and (c) PC index during the period from 1996-2003. As evident in Fig. 6, the semiannual variation of geomagnetic activity is well established (Russell \& McPherron 1973). However, Cliver et al. (2000) suggested that the semiannual variation of the index seemed to be more closely associated with the equinoctial effect rather than the Russell-McPherron effect. As shown in Fig. 6, the apparent monthly averaged variations of the Dst and AL index is also noted. The maximum value in the Dst index were recorded in June and the minimum value was registered in October. The monthly average variation of the Dst index shows distinct characteristics with peaks during the equinoctial season whereas the average PC index according to the month shows higher values in autumn than in spring as shown in Fig. 6. The Dst, AL, PC indices with the average values and standard deviations were found to be $-16.8 \pm 7.4,-132.4 \pm 20.4$, and $1.1 \pm 0.1$, respectively. The monthly averaged AL index of the entire period was $-132.4 \mathrm{nT}$ while the minimum in October was $27.5 \%$ lower and the maximum in January was $25.1 \%$ higher than the average values. According to Vennerstrøm et al. (1991), the seasonal dependence occurs because fieldaligned current becomes a dominant source in winter while the ionospheric conductivity is high during summer. To understand the relationship between solar wind parameters

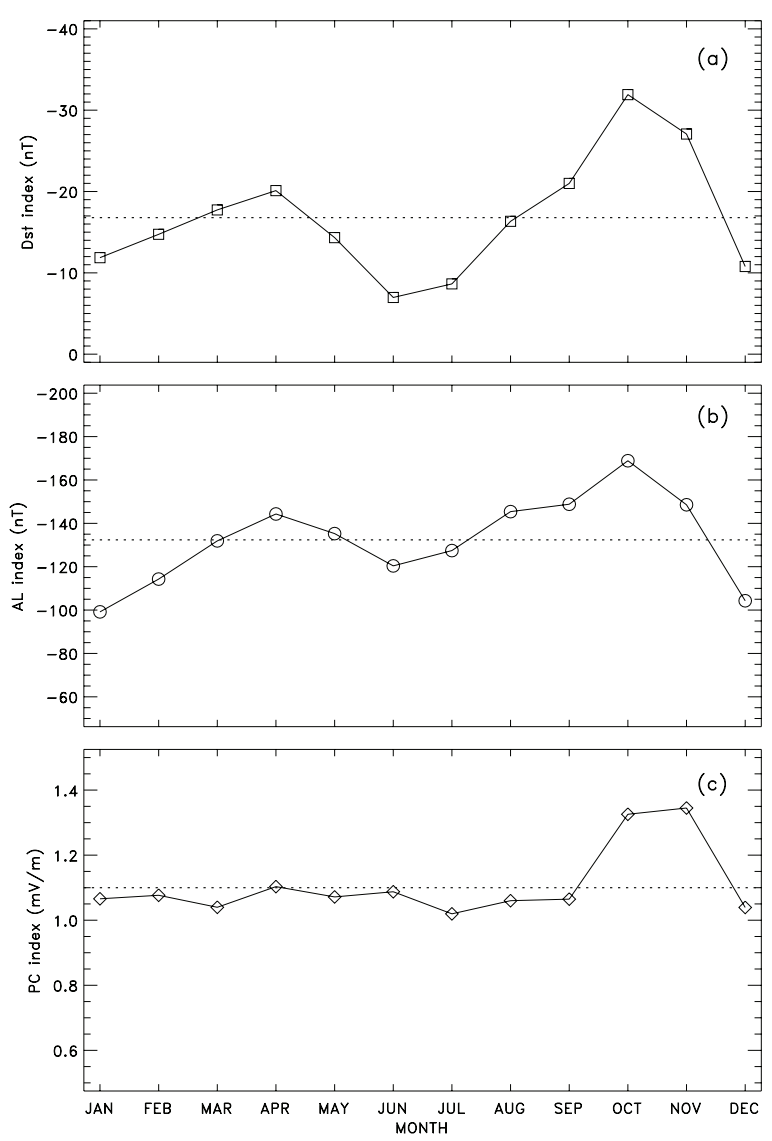

Fig. 6. The monthly averaged variation of AL, Dst, and PC indices.

and geomagnetic indices, the monthly variations of the linear correlations coefficients for PC- $B_{z}, \mathrm{PC}-E_{y}, E_{y}-\mathrm{AL}, \mathrm{PC}-$ Dst, Dst-AL, and PC-AL relations during 1996-2003 are examined, respectively. In Fig. 7, the horizontal axis notes the month and the dashed curves are the fourth-order polynomial fit to the data. The filled small circles in each panel notes the monthly correlation coefficient. As shown in Fig. 7, the average correlation coefficient between the PC and $\mathrm{AL}$ indices is highest being 0.82 whereas the correlation coefficient between the PC and Dst indices is lowest being 0.50 . This may mean energy coupling efficiency is important in ionosphere-magnetosphere coupling though Dst is influenced by interplanetary conditions. In Fig. 7, $\mathrm{r}$ (PC-AL) was recorded at the lowest coefficients during June-July, the summer season. The field-aligned currents and Hall currents seem to be a dominant source of the PC index during wintertime when the polar cap is dark in the Northern Hemisphere, and the ionospheric conductivity is near minimum. During the summer, the Hall current of the PC index is more important role than field-aligned current. Thus, the correlation coefficient is lower in summer than 


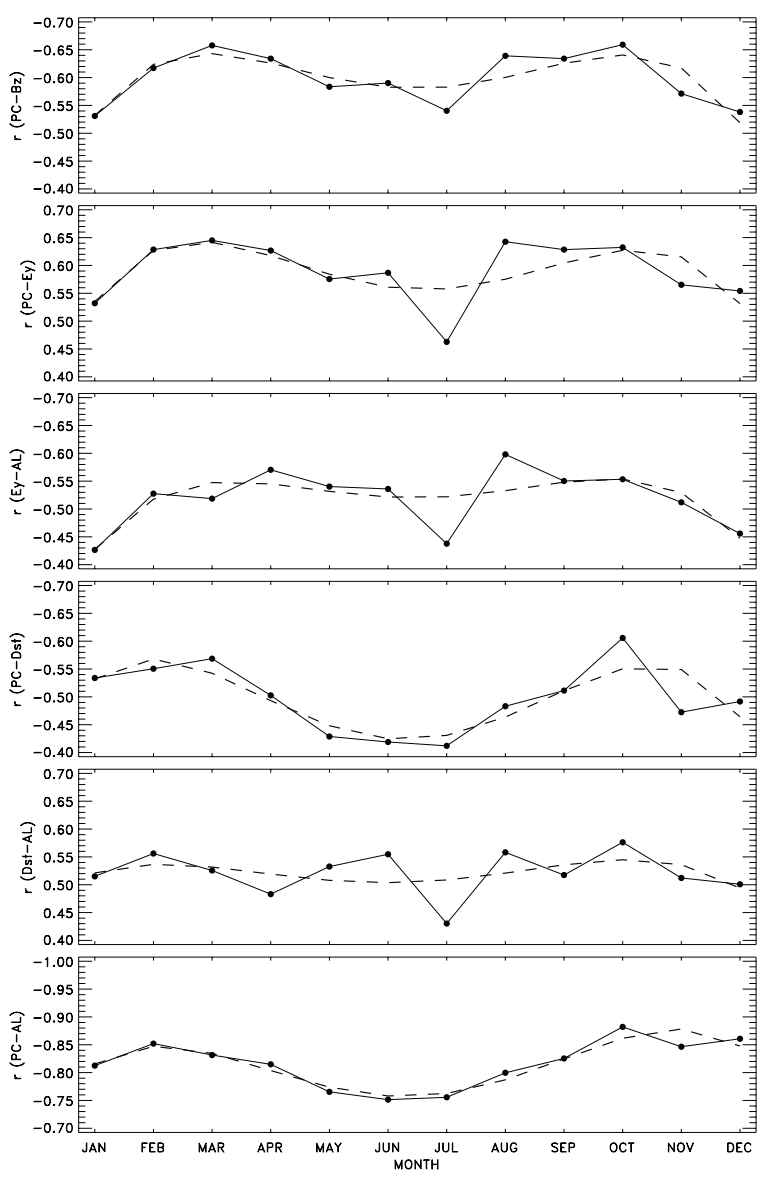

Fig. 7. The monthly variations of the linear correlations coefficients for PC- $B_{z}, P C-E_{y}, E_{y}-A L, P C-D s t$, Dst-AL, and PC-AL relations from top panel to bottom panel during 1996-2003. in winter. To summarize, the PC index appears to be more related to the $\mathrm{AL}$ index than other relationships. In other words, the PC index may be useful as a tool to diagnose an auroral substorm.

\subsection{The Role of the PC Index for the Recovery Phase of Magnetic Storms}

On the basis of Figs. 3 and 4, it is evident that the PC index is more closely related with the AL index than $E_{y}$. In addition, it seems that variations of the PC index are also related to the duration for the recovery phase. It would be meaningful to examine the contribution of the PC index for the recovery phase of magnetic storms. As the recovery phase is the dissipation stage for magnetic storms, a cumulative value is more useful than standard one-toone correspondence. Thus, cumulative PC index are used during magnetic storms. Fig. 8 shows the correlations between cumulative PC index and durations for the three storm categories during the recovery phase. A total of 138 magnetic storms, including 8 severe storms, 32 intense storms, and 98 moderate storms were used. As shown in Fig. 8, it is clear that the average correlation coefficient is high although the correlation coefficient decreases with the storm size. The correlation coefficients are $0.94,0.87$, and 0.74 for moderate, intense, and severe storm, respectively. There is a tendency that the duration of the recovery phase is longer as the PC index increases.
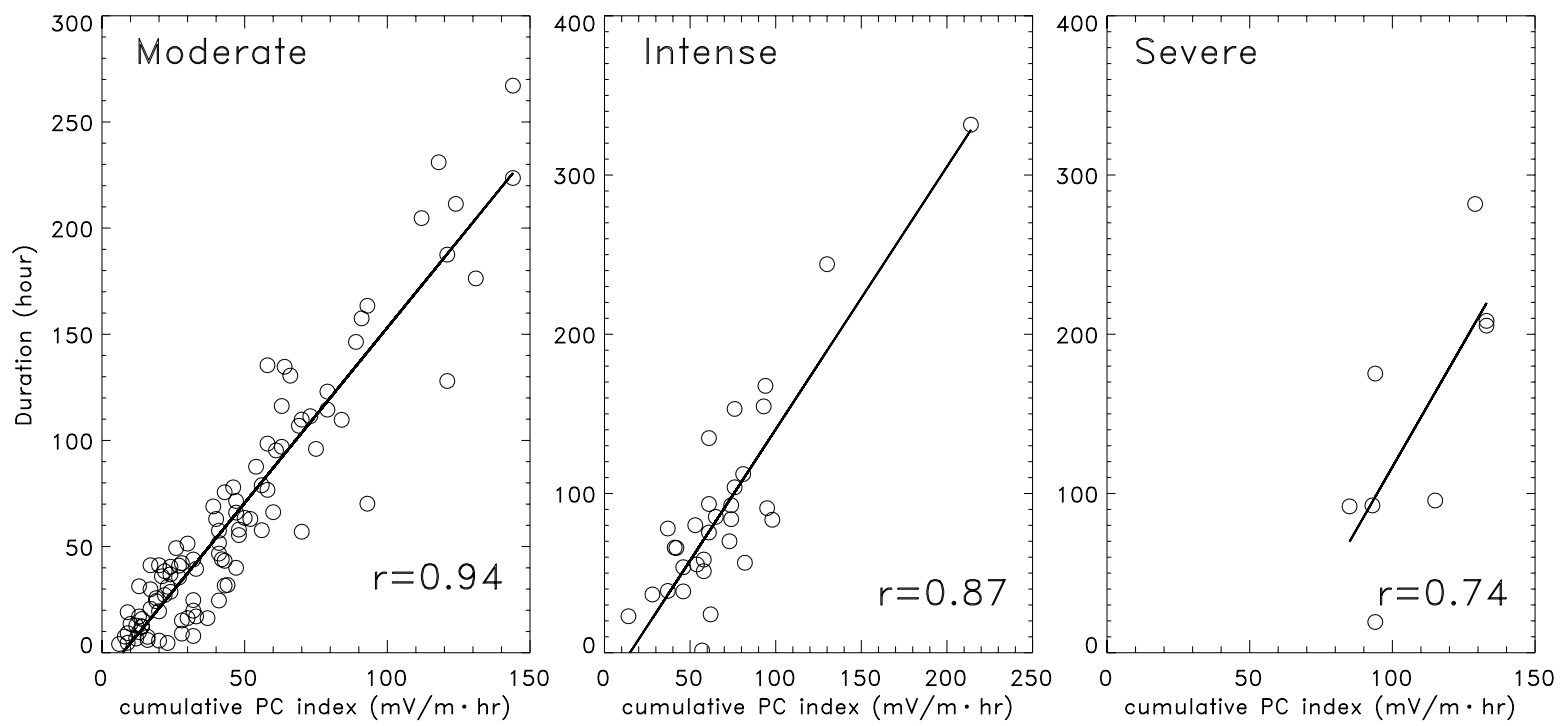

Fig. 8. Relation between cumulative PC index and duration of recovery phase with the storm size. 


\section{SUMMARY AND DISCUSSION}

I estimated the polar cap potential from the relationship between the PC index and calculated merging electric field $\left(E^{*}\right)$ during the 1996-2003 period. To calculate merging electric field, Kan \& Lee's formula (1979) was used in this study. Especially, it is investigated after dividing such into full-time periods and storm-time periods separately. Using Doyle \& Burke (1983)'s empirical relationship, the average polar cap potential is estimated as $58.1 \pm 26.9 \mathrm{kV}$ during fulltime and $123.7 \pm 84.1 \mathrm{kV}$ during storm-time, respectively. The maximum value of polar cap potential is recorded as being $1,266.3 \mathrm{kV}$ on 15 July 2000 . On the other hand, the average value of $E^{*}$ is calculated as 2.77 times higher during storm-time than full-time periods. The PC index is also 3.58 times higher during storm-time than full-time periods.

On the basis of the Russell \& McPherron effect, I compared the monthly averaged variations of Dst, AL, and PC geomagnetic indices. The seasonal variations of Dst and AL indices are similar and show semiannual variations maximizing during the equinoctial season and minimizing during the solstitial season. However, the variations of the PC index show a higher value in autumn than in spring. Also examined are the monthly variations of the linear correlation coefficients for PC- $B_{z}$, PC- $E_{y}, E_{y}-$ $\mathrm{AL}, \mathrm{PC}-\mathrm{Dst}$, Dst-AL, and PC-AL relationships. The average correlation coefficient between the PC and AL indices is highest being 0.82 whereas the correlation coefficient between the PC and Dst index is lowest being 0.50. During summer, the correlation coefficients are shown as the lowest in all relations. Although $\mathrm{r}$ (PC-AL) recorded the lowest coefficients in June and July, the summer season, the PC index seems to be more related to the $\mathrm{AL}$ index than to other relationships. In other words, the PC index may be useful as a tool to diagnose an auroral substorm.

Admitting that the decay of the ring current is a dominant process of the recovery phase, it would be worth examining the contribution of the PC index during such. For this purpose, the correlation between the PC index and the duration of the recovery phase was examined. Although the correlation coefficient lowers with the storm size, it is clear that the average correlation coefficient is high. The correlation coefficients are $0.94,0.87$, and 0.74 for moderate, intense, severe storm, respectively. There is a tendency that the duration of the recovery phase is longer as the PC index increases. These results may be important to study the actual role of the PC index during the recovery phase.

In the early days, Troshichev et al. (1996) showed the statistical dependence of the polar cap diameter on the PC index of magnetic activity from the EXOS D spacecraft from
January to June, 1990. Their results of the polar cap potential differ from other results, including my own. This is because the data set and methods are different and are accomplished in separate manners. Recently, the PC index was discussed at the International Association of Geomagnetism and Aeronomy (IAGA) meeting and is still a controversial topic within the IAGA. Pointing out that the descriptions of the derivation procedures are found not to be adequate to independently derive the actual PC indices, McCreadie \& Menvielle (2010) emphasize the importance of the PC index derivation in order to endorse such as an official index. A full research of the PC index may be necessary in the future. Nevertheless, researchers have reported on various subjects in terms of the PC index.

\section{ACKNOWLEDGMENTS}

I wish to thank the Danish Meteorological Institute for the PC index and the World Data Center for GeomagnetismKyoto for the Dst and AL indices.

\section{REFERENCES}

Borovsky JE, Denton MH, Differences between CME-driven storms and CIR-driven storms, JGR, 111, 11447-11463 (2006). http://dx.doi.org/10.1029/2005JA011447

Chun FK, Knipp DJ, McHarg MG, Lacey JR, Lu G, et al., Joule heating patterns as a function of polar cap index, 107, 1119-1127(2002). http://dx.doi.org/10.1029/ 2001JA000246

Cliver EW, Kamide Y, Ling AG, Mountains versus valleys: semiannual variation of geomagnetic activity, 105, 24132424 (2000). http://dx.doi.org/10.1029/1999JA900439

Doyle MA, Burke WJ, S3-2 Measurements of the polar cap potential, JGR, 88, 9125-9133 (1983). http://dx.doi.org/ 10.1029/JA088iA11p09125

Kan JR, Lee LC, Energy coupling function and solar windmagnetosphere dynamo, GeoRL, 6, 577-580 (1979). http://dx.doi.org/10.1029/GL006i007p00577

Lyatskaya S, Lyatsky W, Khazanov GV, Relationship between substorm activity and magnetic disturbances in two polar caps, GeoRL, 35, L20104 (2008). http://dx.doi. org/10.1029/2008GL035187

McCreadie $\mathrm{H}$, Menvielle $\mathrm{M}$, The PC index: review of methods, AnGeo, 28, 1887-1903 (2010). http://dx.doi. org/10.5194/angeo-28-1887-2010

Nagatsuma T, Conductivity dependence of cross-polar potential saturation, JGR, 109, A04210 (2004). http:// 
dx.doi.org/10.1029/2003JA010286

Perreault P, Akasofu S-I, A study of geomagnetic storms, GeoJ, 54, 547-573 (1978). http://dx.doi.org/10.1111/ j.1365-246X.1978.tb05494.x

Ridley AJ, Kihn EA, Polar cap index comparisons with AMIE cross polar cap potential, electric field, and polar cap area, GeoRL, 31, L07801 (2004). http://dx.doi. org/10.1029/2003GL019113

Russell CT, McPherron RL, Semiannual variation of geomagnetic activity, JGR, 78, 92-108 (1973). http:// dx.doi.org/10.1029/JA078i001p00092

Takalo J, Timonen J, On the relation of the AE and PC indices, JGR, 103, 29393-29398 (1998). http://dx.doi. org/10.1029/98JA02390

Troshichev O, Hayakawa H, Matsuoka A, Mukai T, Tsuruda $\mathrm{K}$, Cross polar cap diameter and voltage as a function of PC index and interplanetary quantities, JGR, 101, 1342913436 (1996). http://dx.doi.org/10.1029/95JA03672

Troshichev O, Janzhura A, Relationship between the PC and AL indices during repetitive bay-like magnetic disturbances in the auroral zone, JASTP, 71, 1340-1352 (2009). http://dx.doi.org/10.1016/j.jastp.2009.05.017

Troshichev OA, Andrezen VG, The relationship between interplanetary quantities and magnetic activity in the southern polar cap, P\&SS 33, 415-419 (1985). http:// dx.doi.org/10.1016/0032-0633(85)90086-8

Troshichev OA, Andrezen VG, Vennerstrøm S, FriisChristensen E, Magnetic activity in the polar cap--a new index, P\&SS, 36, 1095-1102 (1988). http://dx.doi. org/10.1016/0032-0633(88)90063-3

Troshichev OA, Kuznetsov BM, Dmitrieva NP, Polar cap magnetic activity as a signature of substorm development, P\&SS, 27, 217-221 (1979). http://dx.doi. org/10.1016/0032-0633(79)90063-1

Troshichev OA, Lukianova RY, Relation of PC index to the solar wind parameters and substorm activity in time of magnetic storms, JASTP, 64, 585-591 (2002). http:// dx.doi.org/10.1016/S1364-6826(02)00016-0

Troshichev OA, Lukianova RY, Papitashvili VO, Rich FJ, Rasmussen O, Polar cap index (PC) as a proxy for ionospheric electric field in the near-pole region, GeoRL, 27, 3809-3812(2000). http://dx.doi. org/10.1029/2000GL003756

Vennerstrøm S, Friis-Christensen E, Troshichev OA, Andresen VG, Comparison between the polar cap index PC and the auroralelectrojetindicies AE, AL, and AU, JGR, 96, 101-113 (1991). http://dx.doi.org/10.1029/90JA01975 